\title{
MASSIVE CARBAMAZEPINE POISONING
}

The clinical features in 28 consecutive adult cases of laboratory confirmed massive overdosage with CBZ alone treated in an intensive care unit during the period 1981-1991 are reported from Southern Hospital, Karolinska Institute, Stockholm, Sweden. Serum levels at or above $40 \mathrm{mg} / \mathrm{L}$ were significantly associated with an increased risk of serious complications including coma, seizures, respiratory failure and cardiac conduction defects. Two patients died. In $61 \%$ CBZ had been used therapeutically for the treatment of epilepsy. Five patients with repeated generalized seizures despite CBZ concentrations above $40 \mathrm{mg} / \mathrm{L}$ were controlled with diazepam or clonazepam intravenously. Ataxia, vertigo, nystagmus, diplopia, dysarthria, and/or dyskinesia were recorded in 11 cases (39\%). Multiple dose activated charcoal was administered routinely. (Hojer J et al. Clinical features in 28 consecutive cases of laboratory confirmed massive poisoning with carbamazepine alone. Clin Toxicol Sept 1993; $\underline{11}: 449-458)$. (Reprints: Dr Jonas Hojer, Medical Intensive Care Unit, Sodersjukhuset (Southern Hospital), S-118 83, Stockholm, Sweden).

COMMENT. An increased risk of seizures was a sign of CBZ overdose in this study, but in at least six previous reports, one involving 26 well documented cases in children, carbamazepine induced exacerbation of seizures at therapeutic dose levels. (see Ped Neur Briefs June 1987; Progress in Pediatric Neurology, 1991, pp 108-9). The epileptic syndromes worsened by CBZ included childhood absence, LennoxGastaut, myoclonic epilepsy, focal frontal lobe, and generalized tonicclonic epilepsy. A slow withdrawal of the CBZ results in improved seizure control.

\section{PHENOBARBITAL IN NEONATAL SEIZURES}

Phenobarbital plasma levels $24 \mathrm{hrs}$ after a loading dose, and drug level variations after intravenous maintenance doses, were studied in 25 newborns with seizures admitted to a neonatal intensive care unit at the MaternitySchool Hospital of Vila Nova Cachoeirinha, Sao Paulo, Brazil. With a mean loading dose of $19 \mathrm{mg} / \mathrm{kg}$ for both term and pre-term infants and a mean maintenance dose of $4 \mathrm{mg} / \mathrm{kg} /$ day, a mean plasma level of $23 \mathrm{mcg} / \mathrm{ml}$ was obtained at $24 \mathrm{hrs}$, and therapeutic levels between $15-40 \mathrm{mcg} / \mathrm{ml}$ were sustained at 4, 7, 14 and 21 days. A tendency towards drug accumulation in the first week and lower levels after 7 days requires frequent monitoring and dose adjustments. Seizure control without EEG confirmation was obtained in $64 \%$. Phenytoin iv was required in addition in 7 infants and clonazepam in 5. Side effects were limited to infants with severe neurological impairment. (Gherpelli JLD et al. Phenobarbital in newborns with neonatal seizures. A study of plasma levels after intravenous administration. Brain \& Development July/Aug 1993;15:258-262). (Respond: Dr JLD Gherpelli, Sevico de Neurologia Infantil, 